\title{
Early neonatal echocardiographic findings in an experimental rabbit model of congenital diaphragmatic hernia
}

\author{
P.H. Manso ${ }^{1}$, R.L. Figueira ${ }^{2}$, C.M. Prado ${ }^{3}$, F.L. Gonçalves ${ }^{2}$, A.L.B. Simões ${ }^{2}$, \\ S.G. Ramos ${ }^{3}$ and L. Sbragia ${ }^{2}$
}

${ }^{1}$ Departamento de Pediatria, Faculdade de Medicina de Ribeirão Preto, Universidade de São Paulo, Ribeirão Preto, SP, Brasil

${ }^{2}$ Departamento de Cirurgia e Anatomia, Faculdade de Medicina de Ribeirão Preto, Universidade de São Paulo, Ribeirão Preto,

SP, Brasil

${ }^{3}$ Departamento de Patologia, Faculdade de Medicina de Ribeirão Preto, Universidade de São Paulo, Ribeirão Preto, SP, Brasil

\begin{abstract}
This study aimed to demonstrate that congenital diaphragmatic hernia (CDH) results in vascular abnormalities that are directly associated with the severity of pulmonary hypoplasia and hypertension. These events increase right ventricle (RV) afterload and may adversely affect disease management and patient survival. Our objective was to investigate cardiac function, specifically right ventricular changes, immediately after birth and relate them to myocardial histological findings in a $\mathrm{CDH}$ model. Pregnant New Zealand rabbits underwent the surgical procedure at 25 days of gestation $(n=14)$. CDH was created in one fetus per horn $(n=16)$, and the other fetuses were used as controls $(n=20)$. At term (30 days), fetuses were removed, immediately dried and weighed before undergoing four-parameter echocardiography. The lungs and the heart were removed, weighed, and histologically analyzed. $\mathrm{CDH}$ animals had smaller total lung weight $(\mathrm{P}<0.005)$, left lung weight $(P<0.005)$, and lung-to-body ratio $(P<0.005)$. Echocardiography revealed a smaller left-to-right ventricle ratio $(L V / R V$, $\mathrm{P}<0.005)$ and larger diastolic right ventricle size (DRVS, $\mathrm{P}<0.007$ ). Histologic analysis revealed a larger number of myocytes undergoing mitotic division (186 vs 132, $\mathrm{P}<0.05)$ in $\mathrm{CDH}$ hearts. Immediate RV dilation of $\mathrm{CDH}$ hearts is related to myocyte mitosis increase. This information may aid the design of future strategies to address pulmonary hypertension in $\mathrm{CDH}$.
\end{abstract}

Key words: Congenital diaphragmatic hernia; Right ventricle; Pulmonary arterial hypertension; Echocardiography

\section{Introduction}

Congenital diaphragmatic hernia $(\mathrm{CDH})$ is a diaphragm defect that allows abdominal viscera to enter the thorax. This condition occurs in 1 in 2500 live births. Even though patient survival has increased by approximately $85 \%$ over the last decade, $\mathrm{CDH}$ is still associated with a high risk of complications and death, and most neonates with $\mathrm{CDH}$ present signs of respiratory distress within the first hours after birth $(1,2)$. The clinical progression of this disease usually depends more on lung hypoplasia and pulmonary arterial hypertension than on the anatomical defect itself (3). The middle layer of the most distal lung arterioles increases markedly, leading to greater vascular reactivity, hypoxemia, and metabolic acidosis. This situation perpetuates a progressive cycle of vasospasm and causes the clinical status of the patient to deteriorate under conventional treatment (4).
The increase and maintenance of pulmonary vascular resistance (PVR) after birth gives rise to right-to-left blood shunting in the fetal circulation. This may cause right ventricular (RV) dysfunction and failure associated with decreased left ventricle ejection fraction (LVEF) $(5,6)$. Patients with $\mathrm{CDH}$ might present with anatomic and echocardiographic alterations of the left cardiac chambers (LV) $(7,8)$, making the systemic circulation more dependent on the RV and exacerbating LV dysfunction (7). Additionally, the follow-up of children with $\mathrm{CDH}$ has demonstrated that altered RV function exists years after surgical correction (9). Given the importance of secondary cardiac function and pulmonary alterations in $\mathrm{CDH}$, we performed an echocardiographic evaluation of the heart in a rabbit model of $\mathrm{CDH}$ (1) to verify whether myocardiac

Correspondence: L. Sbragia: <sbragia@fmrp.usp.br>.

Received June 17, 2014. Accepted November 13, 2014. First published online February 3, 2015. 
function exhibits primary or secondary alterations after birth and to correlate the data with histological findings.

\section{Material and Methods}

\section{Animals}

This study was approved by the Institutional Ethics Committee on Animal Research (CAR 179-2011; FMRPUSP). Twelve time-mated pregnant New Zealand rabbits were obtained at day 25 of gestation (term $=30$ days). The animals were housed in separate cages at room temperature under normal daylight with water and chow ad libitum.

\section{Surgical procedure}

Pregnant rabbits $(n=14)$ underwent surgery on day 25 of gestation as previously described (10). Under general anesthesia and prophylactic antibiotic therapy, the uterus was exposed via a midline laparotomy. A total of 16 fetuses (1 end-ovarian fetus per rabbit) underwent partial resection of the diaphragm through a left lower thoracotomy $(\mathrm{CDH}$ group), and 20 non-manipulated fetuses were used as controls (control group). The surgical procedure was conducted on each uterine horn, so that each rabbit bore a total of 2 fetuses with $\mathrm{CDH}$. The fetuses were collected 5 days after surgery, under the same conditions as the first procedure. After abdominal and uterine incision, $\mathrm{CDH}$ and control fetuses were removed from the uterus, cleaned, dried, and weighed on an analytic scale. Then, the pregnant rabbit was sacrificed under anesthesia with $1 \mathrm{~mL}$ intravenous $\mathrm{KCl}$ administered into the auricular vein.

\section{Echocardiographic procedure}

After delivery, fetuses were placed on a pre-heated $\left(37^{\circ} \mathrm{C}\right)$ procedure pad, and oxygen supply ( $\left.2 \mathrm{~L} / \mathrm{min}\right)$ was maintained during echocardiography on a Vevo 2100 apparatus (Visualsonics ${ }^{\circledR}$, Canada) that takes 2-3 min for each rabbit (Figure 1). The left and right chambers were measured on parasternal and four-chamber views, and LVEF was obtained in the bidimensional mode from a parasternal long axis view. The following parameters were analyzed: left-to-right ventricle (LV/RV) ratio, diastolic RV size (DRVS), RV anterior wall (RVAW), and LVEF. After echocardiography, the neonates were anesthetized and sternotomized to confirm $\mathrm{CDH}$ before the lungs and heart were removed.

\section{Morphological evaluation}

To evaluate the effect of $\mathrm{CDH}$ on lung growth, body weight (BW, g) and total lung weight (TLW) were measured, and the TLW/BW ratio was calculated.

\section{Histological evaluation}

Tissues were sectioned in the longitudinal plane, stained with hematoxylin-eosin, and photographed under a Leica microscope (Leica DMR, Leica Microsystems, Germany) and a video camera (Leica DC300F, Leica Microsystems). Both ventricles from each heart were isolated and cut into two fragments with a mid-ventricular coronal section. Each block was serially cut in the same direction, and 4- $\mu$ m-thick sections were stained with hematoxylin-eosin. The following histological parameters were measured: a) smaller cardiomyocyte diameter, b) larger and smaller diameters of the nucleus, and c) number of mitotic myocytes using the program Leica Qwin (Leica Imaging Systems Ltd.). Each diameter was measured 154 and 124 times in a total of 33 and 25 different fields in the control and CDH groups, respectively ( $n=5$ in each group). The number of mitotic cardiomyocytes was counted in 50 and 40 different fields in the control and $\mathrm{CDH}$ groups, respectively.

\section{Statistical analysis}

Morphological variables are reported as mean $\pm S D$ and compared with unpaired Student's $t$-tests. Multiple comparisons between the $\mathrm{CDH}$ and control groups were made with one-way analysis of variance (ANOVA) followed by TukeyKramer post hoc tests. Differences were considered significant at $\mathrm{P}<0.05$.

\section{Results}

The survival rate in 14 pregnant rabbits was $100 \%$. The survival rate of fetuses with surgically created $\mathrm{CDH}$ was 16 of $26(61 \%)$. The postmortem examination revealed that all
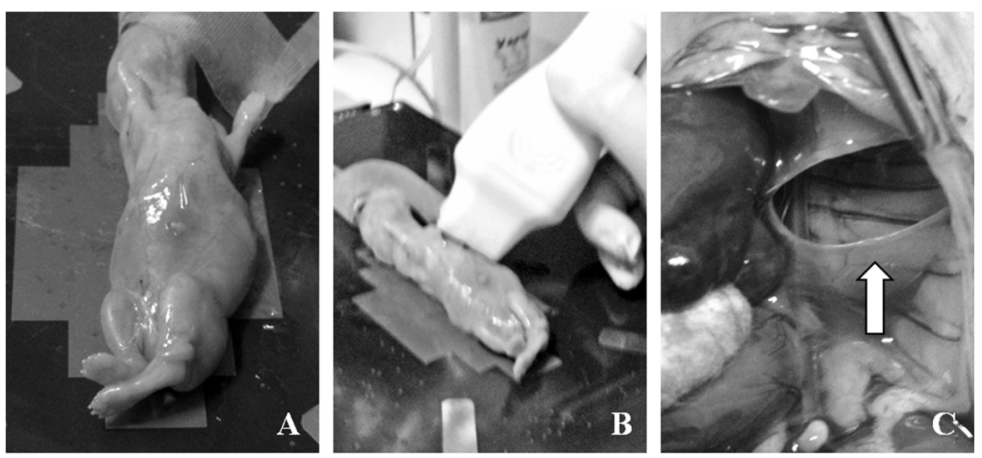

Figure 1. Echocardiographic procedure. A, Neonatal rabbit placed on a pre-heated procedure pad; $B$, examination recording, and $C, \mathrm{CDH}$ confirmation (arrow). 
Table 1. Anatomical data of control and congenital diaphragmatic hernia $(\mathrm{CDH})$ groups.

\begin{tabular}{lll}
\hline & Control $(n=16)$ & CDH $(n=16)$ \\
\hline Body weight $(\mathrm{g})$ & $34.17 \pm 6.24$ & $31.97 \pm 6.44$ \\
Total lung weight $(\mathrm{g})$ & $0.860 \pm 0.246$ & $0.524 \pm 0.138^{*}$ \\
Left lung weight $(\mathrm{g})$ & $0.377 \pm 0.084$ & $0.181 \pm 0.048^{*}$ \\
Heart weight $(\mathrm{g})$ & $0.235 \pm 0.043$ & $0.221 \pm 0.036$ \\
Lung/body ratio $(\%)$ & $0.026 \pm 0.007$ & $0.017 \pm 0.005^{*}$ \\
\hline
\end{tabular}

Data are reported as means $\pm S D$. ${ }^{*} \mathrm{P}<0.005$, compared to control (Student's $t$-test).

the $\mathrm{CDH}$ neonates had diaphragmatic hernias with the liver in the thorax. The control and $\mathrm{CDH}$ groups did not differ in terms of body, heart, or lung weight (Table 1). Echocardiography did not reveal any ejection fraction differences between the groups. The RV diastolic size (RVDS) and LV/ $\mathrm{RV}$ ratio were different in the $\mathrm{CDH}$ and control groups, as the $\mathrm{RV}$ was larger in the $\mathrm{CDH}$ neonates (Table 2 and Figure 2). The histological data also demonstrated an increased number of mitotic myocytes in the $\mathrm{CDH}$ group (Table 3 and Figure 3).

\section{Discussion}

$\mathrm{CDH}$ has an incidence of 0.4 per 1000 live births. It leads to lung hypoplasia and pulmonary arterial hypertension and is associated with neonatal mortality. Over the last several decades, high-frequency mechanical ventilation, inhaled nitric oxide, and extracorporeal membrane oxygenation have increased the survival rate of patients with $\mathrm{CDH}$ to as high as $67 \%(11,12)$ and $80 \%$ in cases with no other associated anomalies (13). The prognosis of $\mathrm{CDH}$ is directly related to the degrees of pulmonary hypoplasia and pulmonary hypertension (11).

The risk of mortality in neonates with $\mathrm{CDH}$ is dependent on several variables, including birth weight, gestational age, initial Apgar score, patch repair, and associated congenital anomalies $(14,15)$. Cardiac anomalies account for approximately $15 \%$ of all $\mathrm{CDH}$ babies treated at referral centers

Table 2. Ecocardiographic data of control and congenital diaphragmatic hernia $(\mathrm{CDH})$ groups.

\begin{tabular}{lll}
\hline & Control $(n=16)$ & CDH $(n=16)$ \\
\hline RVAW $(\mathrm{mm})$ & $0.670 \pm 0.178$ & $0.663 \pm 0.152$ \\
LVEF $(\%)$ & $42.82 \pm 11.25$ & $45.19 \pm 7.59$ \\
DRVS $(\mathrm{mm})$ & $2.914 \pm 0.464$ & $3.331 \pm 0.400^{*}$ \\
LV/RV ratio & $1.208 \pm 0.325$ & $0.920 \pm 0.210^{*}$ \\
\hline
\end{tabular}

Data are reported as means \pm SD. RVAW: right ventricle anterior wall; LVEF: left ventricle ejection fration; DRVS: diastolic right ventricle size; LV/RV ratio: left ventricle/right ventricle ratio. ${ }^{*} \mathrm{P}<0.007$, compared to control (Student's $t$-test).

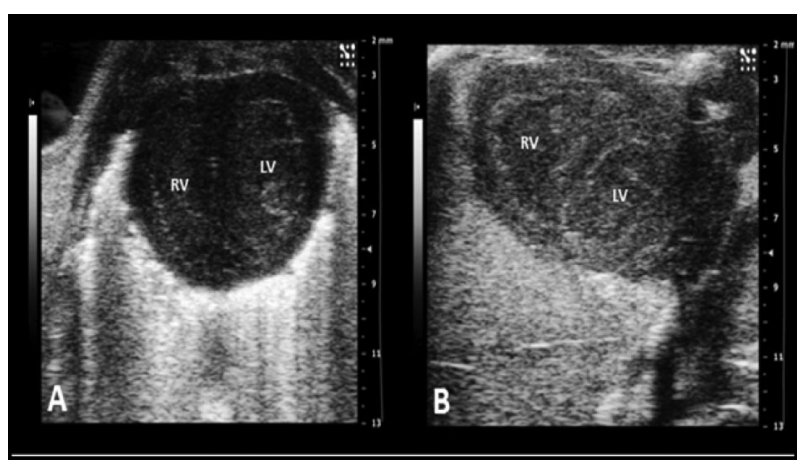

Figure 2. Echocardiographic short axis view from neonatal rabbits. $A$, control group; $B$, congenital diaphragmatic hernia $(\mathrm{CDH})$ group. RV: right ventricle; LV: left ventricle. Note RV enlargement in $\mathrm{CDH}$ group.

$(16,17)$, with significantly lower survival in patients with major heart defects than in those with minor or no heart defects (18). Notably, there were no neonatal rabbits with congenital cardiac anomalies in the present study.

Under normal conditions, pulmonary arterial pressure (PAP) drops by about $50 \%$ within the first 24 hours after birth, whereas the pulmonary flow rises between 8- and 10fold. Such alterations in flow and pressure result in foramen ovale and ductus arteriosus closure. Pulmonary hypoplasia in $\mathrm{CDH}$ patients increases pulmonary arterial resistance and PAP, resulting in continuous blood bypass through these structures, causing blood shunting to the right and consequent hypoxia, progressive respiratory deterioration, metabolic acidosis, and cardiac failure (19-21).

This cardiac overload has motivated researchers to propose fetal echocardiographic examination to predict the outcome of fetuses and neonates with $\mathrm{CDH}(22-24)$. However, no consensus exists, and investigators seem to disagree on LV mass: some authors believe that it is hypoplastic, which could point to a poor outcome (7), whereas others have reported that there is no evidence for this $(25,26)$. It is possible that the cardiac alterations accompanying pulmonary hypoplasia in $\mathrm{CDH}$ have a purely mechanical nature attributable to an intrathoracic hernia (27).

We expected that pulmonary vascular resistance would change and cause pressure overload on the RV only after birth. Nevertheless, we noticed cardiac alterations in the immediate postnatal period. Based on this, we can hypothesize that vascular and cardiac alterations in patients with $\mathrm{CDH}$ start in the uterus. The postnatal pressure overload in the RV might be an additional consequence of a diaphragmatic hernia.

We verified increased RV thickness and a reduced LV/ $\mathrm{RV}$ ratio. Many factors, such as arterial pressure, cardiac function, and oxygenation, have recently been implicated in a higher mortality risk among $\mathrm{CDH}$ patients $(26,28)$. Furthermore, quantification of the LV mass and its shortening fraction measured by echocardiography can also be related 
Table 3. Histological data of control and congenital diaphragmatic hernia (CDH) groups.

\begin{tabular}{lcr}
\hline & Control $(n=5)$ & CDH $(n=5)$ \\
\hline Smaller myocyte diameter $(\mu \mathrm{m})$ & $7.93 \pm 1.25$ & $7.70 \pm 1.16$ \\
Larger diameter of the nucleus $(\mu \mathrm{m})$ & $12.18 \pm 1.59$ & $11.58 \pm 1.96$ \\
Smaller diameter of the nucleus $(\mu \mathrm{m})$ & $4.88 \pm 0.92$ & $4.63 \pm 0.84$ \\
Mitotic myocyte count & 138 & $186^{*}$ \\
\hline
\end{tabular}

Data are reported as means $\pm S D$. * $P<0.05$, compared to control (Student's $t$-test).

to $\mathrm{CDH}$ severity (29). Although the model of surgically created $\mathrm{CDH}$ is well established (10), anatomical distortions secondary to intrathoracic hernia apparently mediate changes in cardiac function, affecting patients' clinical follow-up (30). Correia-Pinto et al. (31) only detected anatomical cardiac alterations in the nitrofen model of $\mathrm{CDH}$ in the initial stages of embryonic heart development. In the present study, the $\mathrm{CDH}$ rabbit model did not show any evidence of heart weight differences at birth.

Our findings indicate that the postnatal overload increase theory cannot fully explain the anatomical cardiac alterations detected in the RV soon after birth. Therefore, we speculate that lung hypoplasia may lead to a signaling process of cardiac and vascular abnormalities that are

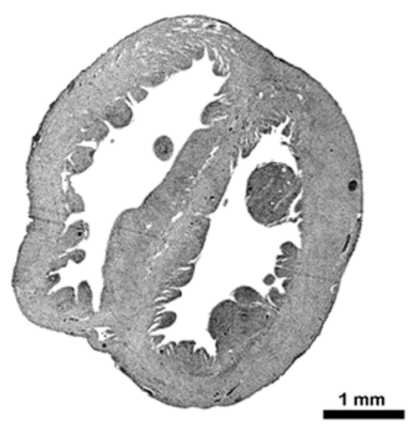

Control
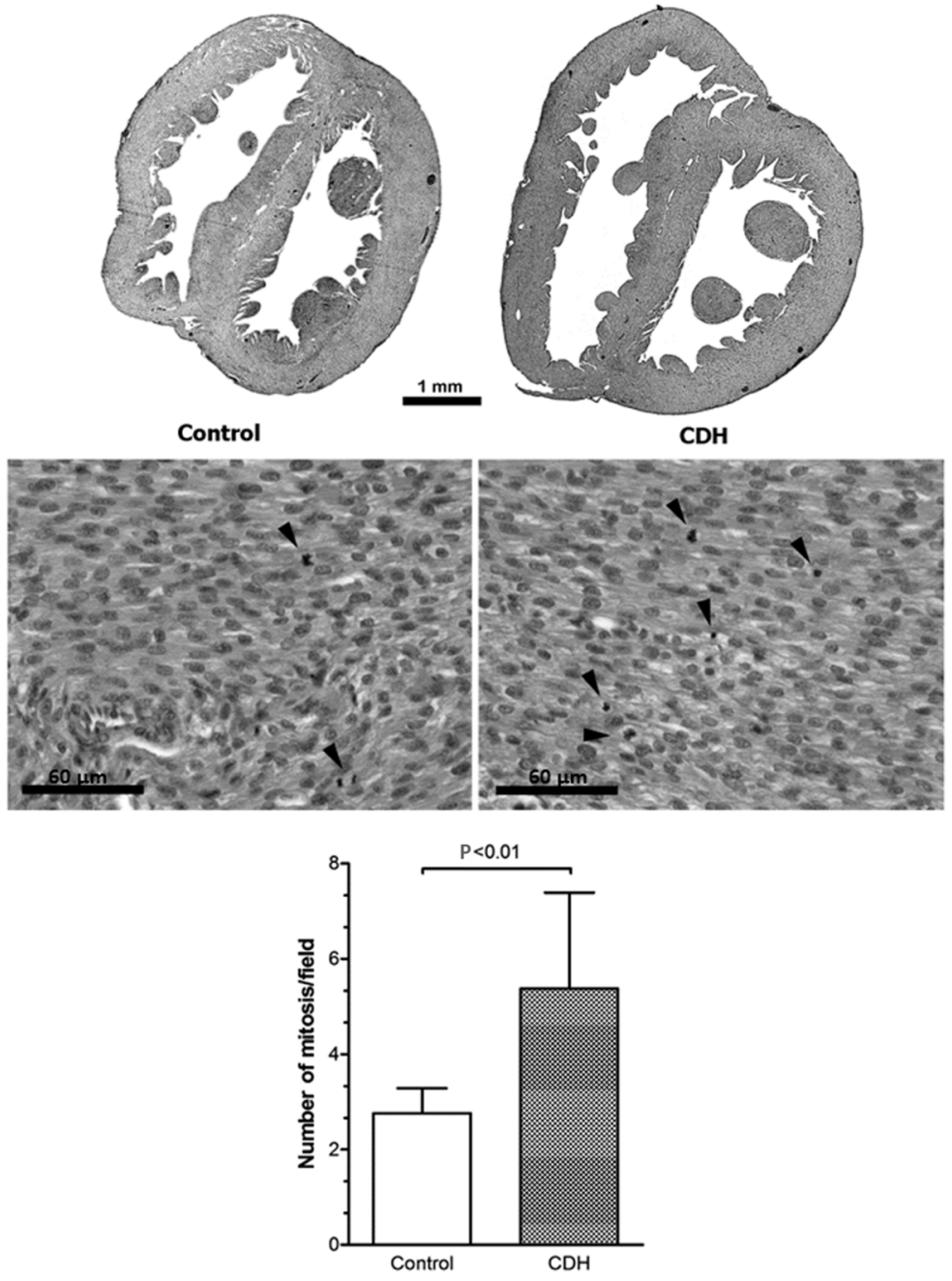

Figure 3. Histological view showing right ventricle dilation in the congenital diaphragmatic hernia $(\mathrm{CDH})$ group. Arrows point to mitosis in right ventricle. There was an increased number of mitotic myocytes in the $\mathrm{CDH}$ group. 
initiated before delivery. Under normal conditions, phosphokinase (PKG) and myocardin activation should contract the smooth muscle cells (SMCs). However, during the $\mathrm{CDH}$ hypoxia status, gene expression in pulmonary artery SMCs is altered, diminishing PKG and myocardin expression and leading to myocyte proliferation. These findings could be extrapolated to the fetal heart to justify increased mitotic division in the RV $(21,32)$.

This study has some limitations. First, the $\mathrm{CDH}$ model used here may not fully mimic embryonic pathology. Moreover, although we identified diaphragmatic hernias in the postmortem examinations of all the specimens in the $\mathrm{CDH}$ group, migration of abdominal viscera into the thoracic cavity may have varied. The fact that the $\mathrm{CDH}$ and control groups had different left lung weights indirectly indicates that our model was successful.

In future studies, placing neonatal rabbits on mechanical

\section{References}

1. Golombek SG. The history of congenital diaphragmatic hernia from 1850s to the present. J Perinatol 2002; 22: 242246, doi: 10.1038/sj.jp.7210701.

2. Javid PJ, Jaksic T, Skarsgard ED, Lee S. Survival rate in congenital diaphragmatic hernia: the experience of the Canadian Neonatal Network. J Pediatr Surg 2004; 39: 657660, doi: 10.1016/j.jpedsurg.2004.01.022.

3. Pober BR. Overview of epidemiology, genetics, birth defects, and chromosome abnormalities associated with CDH. Am J Med Genet C Semin Med Genet 2007; 145C: 158-171, doi: 10.1002/ajmg.c.30126.

4. Mohseni-Bod H, Bohn D. Pulmonary hypertension in congenital diaphragmatic hernia. Semin Pediatr Surg 2007; 16: 126-133, doi: 10.1053/j.sempedsurg.2007.01.008.

5. Lindberg L, Olsson AK, Jogi $P$, Jonmarker $C$. How common is severe pulmonary hypertension after pediatric cardiac surgery? J Thorac Cardiovasc Surg 2002; 123: 1155-1163, doi: $10.1067 / \mathrm{mtc} .2002 .121497$.

6. Buss M, Williams G, Dilley A, Jones O. Prevention of heart failure in the management of congenital diaphragmatic hernia by maintaining ductal patency. A case report. J Pediatr Surg 2006; 41: e9-e11, doi: 10.1016/j.jpedsurg.2006.01.003.

7. Siebert JR, Haas JE, Beckwith JB. Left ventricular hypoplasia in congenital diaphragmatic hernia. J Pediatr Surg 1984; 19 : 567-571, doi: 10.1016/S0022-3468(84)80105-0.

8. Sharland GK, Lockhart SM, Heward AJ, Allan LD. Prognosis in fetal diaphragmatic hernia. Am J Obstet Gynecol 1992; 166: 9-13, doi: 10.1016/0002-9378(92)91817-T

9. Egan MJ, Husain N, Stines JR, Moiduddin N, Stein MA, Nelin LD, et al. Mid-term differences in right ventricular function in patients with congenital diaphragmatic hernia compared with controls. World J Pediatr 2012; 8: 350-354, doi: 10.1007/ s12519-012-0380-2.

10. Fauza DO, Tannuri U, Ayoub AA, Capelozzi VL, Saldiva PH, Maksoud JG. Surgically produced congenital diaphragmatic hernia in fetal rabbits. J Pediatr Surg 1994; 29: 882-886, doi: 10.1016/0022-3468(94)90008-6.

11. Seetharamaiah R, Younger JG, Bartlett RH, Hirschl RB. Factors associated with survival in infants with congenital ventilation might prolong their lifespan and enable later cardiac assessment. The increased myocyte mitotic division found during hypoxia may aid investigations of $\mathrm{CDH}$ neonatal myocardial regeneration. This should be interesting, given that cardiac cells rarely proliferate. Our results of early echocardiographic evaluation of rabbit neonates with $\mathrm{CDH}$ reveals pressure overload on the right ventricle and increased cardiac muscle mitotic activity. Deciphering these early adaptive mechanisms remains a challenge.

\section{Acknowledgments}

We are grateful to Ms. Cynthia Manso for her English language assistance and to CNPq (\#471496/2011-1) and FAPESP (\#2011/00794-1; 2011/12587-0) for financial support.

diaphragmatic hernia requiring extracorporeal membrane oxygenation: a report from the Congenital Diaphragmatic Hernia Study Group. J Pediatr Surg 2009; 44: 1315-1321, doi: 10.1016/j.jpedsurg.2008.12.021.

12. Sluiter I, van de Ven CP, Wijnen RM, Tibboel D. Congenital diaphragmatic hernia: still a moving target. Semin Fetal Neonatal Med 2011; 16: 139-144, doi: 10.1016/j.siny.2011.03. 002.

13. Kaiser JR, Rosenfeld CR. A population-based study of congenital diaphragmatic hernia: impact of associated anomalies and preoperative blood gases on survival. J Pediatr Surg 1999; 34: 1196-1202, doi: 10.1016/S0022-3468(99)90151-3.

14. Congenital Diaphragmatic Hernia Study Group. Estimating disease severity of congenital diaphragmatic hernia in the first 5 minutes of life. J Pediatr Surg 2001; 36: 141-145, doi: 10.1053/jpsu.2001.20032.

15. Lally KP, Lally PA, Lasky RE, Tibboel D, Jaksic T, Wilson JM, et al. Defect size determines survival in infants with congenital diaphragmatic hernia. Pediatrics 2007; 120: e651-e657, doi: 10.1542/peds.2006-3040.

16. Graziano JN. Cardiac anomalies in patients with congenital diaphragmatic hernia and their prognosis: a report from the Congenital Diaphragmatic Hernia Study Group. J Pediatr Surg 2005; 40: 1045-1049, doi: 10.1016/j.jpedsurg.2005.03.025.

17. Lin AE, Pober BR, Adatia I. Congenital diaphragmatic hernia and associated cardiovascular malformations: type, frequency, and impact on management. Am J Med Genet C Semin Med Genet 2007; 145C: 201-216, doi: 10.1002/ajmg.c. 30131.

18. Menon SC, Tani LY, Weng HY, Lally PA, Lally KP, Yoder BA. Clinical characteristics and outcomes of patients with cardiac defects and congenital diaphragmatic hernia. J Pediatr 2013; 162: 114-119, doi: 10.1016/j.jpeds.2012.06.048.

19. Morin FC III, Stenmark KR. Persistent pulmonary hypertension of the newborn. Am J Respir Crit Care Med 1995; 151: 2010-2032, doi: 10.1164/ajrccm.151.6.7767553.

20. de Buys Roessingh AS, de Lagausie P, Ebrahimian T, Duong-Quy S, Schneider JC, Huang XL, et al. Neuronal nitric oxide synthase does not contribute to the modulation 
of pulmonary vascular tone in fetal lambs with congenital diaphragmatic hernia (nNOS in $\mathrm{CDH}$ lambs). Pediatr Pulmonol 2008; 43: 313-321, doi: 10.1002/ppul.20796.

21. Gao Y, Raj JU. Regulation of the pulmonary circulation in the fetus and newborn. Physiol Rev 2010; 90: 1291-1335, doi: 10.1152/physrev.00032.2009.

22. Crawford DC, Wright VM, Drake DP, Allan LD. Fetal diaphragmatic hernia: the value of fetal echocardiography in the prediction of postnatal outcome. Br J Obstet Gynaecol 1989; 96: 705-710, doi: 10.1111/j.1471-0528.1989.tb03286.x.

23. Schwartz SM, Vermilion RP, Hirschl RB. Evaluation of left ventricular mass in children with left-sided congenital diaphragmatic hernia. J Pediatr 1994; 125: 447-451, doi: 10.1016/S0022-3476(05)83293-7.

24. Thebaud B, Azancot A, de Lagausie P, Vuillard E, Ferkadji L, Benali $\mathrm{K}$, et al. Congenital diaphragmatic hernia: antenatal prognostic factors. Does cardiac ventricular disproportion in utero predict outcome and pulmonary hypoplasia? Intensive Care Med 1997; 23: 10062-10069.

25. Sabharwal AJ, Davis CF, Howatson AG. Post-mortem findings in fetal and neonatal congenital diaphragmatic hernia. Eur $\mathrm{J}$ Pediatr Surg 2000; 10: 96-99, doi: 10.1055/s-2008-1072334.

26. Suda K, Bigras JL, Bohn D, Hornberger LK, McCrindle BW. Echocardiographic predictors of outcome in newborns with congenital diaphragmatic hernia. Pediatrics 2000; 105: 1106-1109, doi: 10.1542/peds.105.5.1106.

27. Karamanoukian HL, O'Toole SJ, Rossman JR, Sharma A,
Holm BA, Azizkhan RG, et al. Can cardiac weight predict lung weight in patients with congenital diaphragmatic hernia? J Pediatr Surg 1996; 31: 823-825, doi: 10.1016/S00223468(96)90143-8.

28. Kinsella JP, Ivy DD, Abman SH. Pulmonary vasodilator therapy in congenital diaphragmatic hernia: acute, late, and chronic pulmonary hypertension. Semin Perinatol 2005; 29: 123-128, doi: 10.1053/j.semperi.2005.04.008.

29. Springer SC, Fleming D, Hulsey TC. A statistical model to predict nonsurvival in congenital diaphragmatic hernia. $J$ Perinatol 2002; 22: 263-267, doi: 10.1038/sj.jp.7210681.

30. Baumgart S, Paul JJ, Huhta JC, Katz AL, Paul KE, Spettell $\mathrm{C}$, et al. Cardiac malposition, redistribution of fetal cardiac output, and left heart hypoplasia reduce survival in neonates with congenital diaphragmatic hernia requiring extracorporeal membrane oxygenation. J Pediatr 1998; 133: 57-62, doi: 10.1016/S0022-3476(98)70178-7.

31. Correia-Pinto J, Baptista MJ, Pedrosa C, Estevao-Costa J, Flake AW, Leite-Moreira AF. Fetal heart development in the nitrofen-induced $\mathrm{CDH}$ rat model: the role of mechanical and nonmechanical factors. J Pediatr Surg 2003; 38: 14441451, doi: 10.1016/S0022-3468(03)00494-9.

32. Zhou W, Negash S, Liu J, Raj JU. Modulation of pulmonary vascular smooth muscle cell phenotype in hypoxia: role of cGMP-dependent protein kinase and myocardin. Am J Physiol Lung Cell Mol Physiol 2009; 296: L780-L789, doi: 10.1152/ajplung.90295.2008. 